\title{
RANCANG BANGUN ALAT PENGAYAK PASIR OTOMATIS
}

\author{
Fanni Fattah \\ Dosen Teknik Mesin Universitas Muhammadiyah Tangerang \\ Email :vanfattah@gmail.com
}

\begin{abstract}
ABSTRAK
Melihat kemajuan teknologi dewasa ini yang semakin canggih menuntut kita harus bisa mengikuti perkembangannya, oleh karena penulis ingin mencoba mengaplikasikan ilmu yang penulis pelajari dalam penelitian ini yang didukung dengan penggunaan beberapa teknologi. Sistem kerja alat ini adalah memanfaatkan motor listrik 220 watt sebagai sumber tenaga yang diteruskan ke pui dengan transmisi sabuk V belt, lalu diteruskan keputaran poros yang terpasang eksentrik pada piringan engkol yang mengakibatkan ayuakan berayun dan siap mengayak pasir.

Perancangan mesin pengayak ini dapat dihasilkan dengan diameter puli penggerak $50 \mathrm{~mm}$ dan diameter puli yang digerakkan $300 \mathrm{~mm}$, perbandingan puli pada penggerak dan digerakkan adalah 1:6. Poros utama sebesar $12 \mathrm{~mm}$ dapat menyalurkan daya sebesar 220 watt. Alat ini memiliki sistem transmisi yang digerakkan oleh motor listrik $1 / 2$ Hp 1400 rpm 1 phase. Sabuk yang digunakan adalah tipe A56.

Hasil dari pengayakan dengan pasir $0.012 \mathrm{~m} 3$ dengan kapasitas ayak sebanyak $3630 \mathrm{~kg} / \mathrm{jam}$ didapatkan hasil yang tersaring sebanyak $80 \%$ serta sisa batu dan kerikil yang tidak tersaring sebanyak $20 \%$.
\end{abstract}

Kata kunci : transmisi sabuk, ayakan pasir, motor listrik.

\section{PENDAHULUAN}

Pasir adalah material yang penting dalam bidang konstruksi bangunan, baik untuk bangunan rumah tempat tinggal, tempat ibadah, perkantoran, maupun gedung - gedung sarana pendidikan serta bangunan - bangunan lainnya.Material pasir dengan ukuran seragam seringkali dibutuhkan dalam konstruksi bangunan.Material pasir pada umumnya terdiri dari pasir yang masih bercampur dengan kerikil dan batu.Pasir seperti ini harus diayak terlebih dahulu sebelum digunakan untuk bahan konstruksi bangunan.

Pasir dengan ukuran seragam umumnya didapat dari proses pengayakan manual yang membutuhkan banyak tenaga manusia serta waktu pengayakan yang lama, sehingga perlu dibuat mesin ayak getar untuk meminimalisir penggunaan tenaga manusia dan waktu pengayakan. Penggunaan tenaga manusia pada mesin ini hanya sebagai operator dan penumpah pasir. Disamping itu keuntungan lain yang dapat diperoleh adalah waktu yang digunakan relatif pendek dan hasil produksipun jauh lebih banyak dibandingkan yang menggunakan sistem manual.

Ayakan ini sangat banyak gunanya, bukan saja untuk menyaring material pasir tapi juga berguna untuk menyaring material lain yang akan disesuaikan dengan ukuran saringan, karena bak saringan bisa dibongkar pasang.

\section{Rumusan Masalah}

Adapun kegiatan pekerjaan yang dihadapi penulis ketika menyusun penelitian ini adalah :

1. Berapa besar putaran yang dihasilkan pada poros engkol.

2. Berapa diameter yang digunakan pada puli penggerak dan puli yang digerakan.

3. Apakah mesin ini bisa di bongkar pasang dalam artian kehalusan pasir.

Batasan Masalah

Agar analisa dan perhitungan dalam perancangan Mesin Pengayak Pasir ini tidak melebar, maka diperlukan batasan masalah. Batasan masalah dalam perancangan mesin pengayak pasir ini yaitu :

1. Penulis tidak menjelaskan kehalusan pasir.

2. Penulis tidak menghitung rangka beserta gaya - gayanya pada benda kerja.

3. Penulis tidak menghitung poros pada piringan engkol.

\section{Tujuan Penulisan}

Adapun tujuan penulisan laporan penelitian ini adalah :

1. Sebagai salah satu syarat untuk memenuhi dan dapat menyelesaikan pendidikan program sarjana Teknik Mesin di Universitas Muhammadiyah Tangerang.

2. Untuk dapat menerapkan materi - materi ilmu yang diperoleh selama dibangku kuliah.

3. Dengan adanya perencanaan alat ini penulis akan lebih mengerti tentang bagaimana cara mengatasi berbagai permasalahan yang timbul dalam perencanaan dengan bekal ilmu yang penulis miliki.

4. Dapat mengetahui cara yang benar dalam merencanakan suatu alat sehingga alat yang dibuat dapat bermanfaat sesuai sesuai dengan fungsinya dan mempunyai nilai produksi yang baik. 
5. Untuk menambah wawasan mengenai proses dari suatu perencaan ayakan pasir bagi penulis khususnya dan para pembaca pada umumnya.

\section{LANDASAN TEORI}

\subsection{Penggunaan Pasir Sebagai Bahan Bangunan}

Pasir adalah bahan bangunan yang banyak dipergunakan dari struktur paling bawah hingga paling atas dalam bangunan.Baik sebagai pasir urug, adukan hingga campuran beton. Beberapa pemakaian pasir dalam bangunan dapat kita jumpai seperti :

\subsubsection{Penggunaan Sebagai Urugan} lain - lain.

Misalnya pasir urug bawah pondasi, pasir urug bawah lantai, pasir urug dibawah pemasangan paving block dan

\subsubsection{Penggunaan Sebagai Mortar atau Spesi}

Biasanya digunakan sebagai adukan untuk lantai kerja, pemasangan pondasi batu kali, pemasangan dinding bata, spesi untuk pemasangan keramik lantai dan keramik dinding, spesi untuk pemasangan batu alam, plesteran dinding dan lain - lain.

\subsubsection{Penggunaan Sebagai Campuran Beton}

Baik untuk beton bertulang maupun tidak bertulang, bias kita jumpai dalam struktur pondasi beton bertulang, sloof, lantai, kolan, plat lantai, cor dak, ring balok dan lain - lain.

Disamping itu masih banyak penggunaan pasir dalam bahan bangunan yang dipergunakan sebagai bahan campuran untuk pembuatan material cetak seperti pembuatan paving block, kansteen, batako dan lain - lain. Ada beberapa jenis pasir yang bisa dijual diantaranya :

\subsubsection{Pasir Beton}

Pasir beton biasanya berwarna hitam dan butirannya cukup halus, namun apabila dikepal dengan tangan tidak menggumpal dan akan puyar kembali. Pasir ini baik sekali untuk pengecoran, plesteran dinding, pondasi, juga pemasangan bata dan batu.

\subsubsection{Pasir Pasang}

Pasir pasang adalah pasir yang lebih halus dari pasir beton ciri cirinya apabila dikepal dia akan menggumpal tidak kembali lagi ke semula. Pasir pasang biasanya dipakai untuk campuran pasir beton agar tidak terlalu kasar sehingga bisa dipakai untuk plesteran dinding.

\subsubsection{Pasir Elod}

Pasir elod adalah pasir yang paling halus dibandingkan pasir beton dan pasir pasang. Ciri ciri pasir elod adalah apabila dikepal dia akan menggumpal dan tidak akan puyar kembali. Pasir ini masih ada campuran tanahnya dan warnanya hitam.Jenis pasir ini tidak bagus untuk bangunan, pasir ini biasanya hanya untuk campuran pasir beton agar bisa digunakan untuk plesteran dinding, atau untuk campuran pembuatan batako.

\subsubsection{Pasir Merah}

Pasir merah atau suka disebut pasir jebrod kalau di daerah sukabumi cianjur karena pasirnya diambil dari daerah jebrod cianjur. Pasir jebrod biasanya bagus untuk bahan cor karena cirinya hampir sama dengan pasir beton namun lebih kasar dan batuannya agak lebih besar.

\subsection{Dasar-dasar Pemilihan Bahan}

Pengetahuan dasar dalam pemilihan bahan yang akan digunakan merupakan suatu kebutuhan yang sangat penting sebelum merancang alat atau suatu mesin. Seorang perancang terlebih dahulu harus mengerti dan memahami langhah-langkah dalam proses pembuatan suatu alat mesin yang direncanakan untuk selanjutnya dapat menentukan dan memilih bahan sesuai untuk digunakan.

Dari hal tersebut diatas maka dalam merencanakan ayakan pasir ini selain kekuatan bahan juga berdasarkan hal sebagai berikut :

\subsubsection{Kondisi Kerja Alat}

Karena ayakan mengalami gaya berayun yang tinggi maka dalam pemilihan bahannya haruslah yang tahan terhadap ayunan dan ulet terhadap gaya-gaya yang bekerja, dan untuk perencanaan ini bahan yang dominan digunakan adalah baja.

\subsubsection{Penggunaan Komponen-komponen Standar}

Untuk memudahkan dalam proses perawatan dan perbaikan maka bagian-bagian yang diperkirakan cepat rusak atau aus seperti baut dan bantalan, maka dapat menggunakan komponen standar. Penggunaan komponen standar ini berfungsi untuk efisiensi waktu karena komponen tersebut susah untuk dibuat.

\subsubsection{Bahan Mudah Didapat}


Dalam perencanaan ini bahan yang digunakan diutamakan bahan yang banyak terdapat dipasaran, sehingga dalam proses pembuatan dapat berjalan lancar sesuai dengan yang direncanakan.

\subsection{Bahan Yang Digunakan}

Berdasarkan bahan yang dikemukan diatas, maka bahan yang dominan digunakan dalam perencanaan ayakan pasir ini adalah :

\subsubsection{Material Untuk Rangka}

Dalam industry mesin, material untuk kontruksi rangka mesin pengayak mendapat perhatian khusus jenis logam yang dipakai sangat menentukan kekuatan dalam menahan beban yang terjadi saat mesin bekerja, terutama yang berhubungan dengan kestabilan dan elastisitasnya terhadap getaran.Kekuatan kontruksi mesin juga dipengaruhi oleh logam bahannya. Material yang digunakan dapat dibedakan atas beberapa kelompok yaitu :

\subsubsection{Besi Kasar (besi tuang)}

Merupakan besi perkakas tanpa campuran, yang terdiri dari besi $(\mathrm{Fe})$ dan karbon C 1,7\% sampai 4,5\% baik digunakan pada kontruksi kaki atau standar mesin.

\subsubsection{Baja Untuk Bangunan dan Baja Kontruksi}

Merupakan baja tanpa campuran, yang terdiri dari besi dan karbon maksimal (0,45\% C). Digunakan pada besi profil, seng, pasak pasang, kawat, standar atau kaki mesin.

\subsubsection{Baja Perkakas Tanpa Campuran}

Baja yang terdiri $0,45 \%$ sampai 1,7\% karbon dan besi. Bila dikeraskan, baja ini dapat digunakan sebagai bahan perkakas mesin sederhana.Tanpa pengerasan baja ini biasanya diguakan untuk perkakas tangan saja.

\subsubsection{Baja Perkakas Lapis}

Merupakan baja yang dibuat dari Fe dan logam campuran krom, kobalt, wolfram dan nikel.Digunakan untuk pembuatan perkakas tangan bermutu baik atau perkakas mesin yang berdaya guna tinggi.

\subsubsection{Logam Keras}

Logam yang terdiri dari wolfram dan zat arang karbon (C) ditambah kobalt sintesis, digunakan untuk bahan perkakas mesin.

\subsubsection{Motor Listrik}

Motor listrik adalah suatu komponen utama dari sebuah kontruksi permesinan yang berfungsi sebagai penggerak (Lihat gambar 2.1)! Gerakan yang dihasilkan oleh motor adalah sebuah putaran poros. Komponen lain yang dihubungkan dengan poros motor adalah pulley yang kemudian dihubungkan dengan sabuk V-belt.

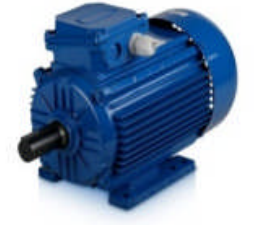

\section{Gambar 2.1 Motor listrik}

Motor listrik merupakan suatu alat yang berfungsi mengubah energi listrik menjadi energi mekanik (gerak). Gerakan yang ditimbulkan adalah gerakan berputar. Motor listrik banyak digunakan sebagai penggerak dalam mesin-mesin industri. Motor listrik dapat berputar diakibatkan karena peristiwa elektro magnetik, gaya yang menyebabkan motor dapat bergerak gaya yang timbul pada suatu kawat berarus yang melintasi/memotong medan magnet.

Gaya ini dimanfaatkan untuk menggerakkan motor berputar. Secara konstruksi motor listrik terdiri dari magnet dan kumparan. Magnet digunakan untuk menghasilkan medan magnet, sedang kumparan sebagai lintasan kawat yang memotong medan magnet. Konstruksi dalam sebuah motor listrik dapat dilihat pada gambar 2.2.

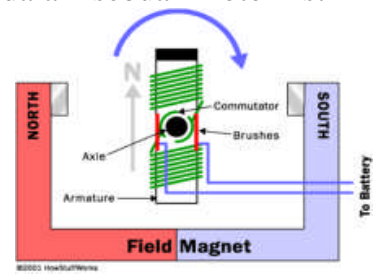

Gambar 2.2 Cara Kerja Motor Listrik

Dari gambar tersebut dapat dilihat, medan magnet akan terbentuk diantara kutub Utara dan Selatan magnet. Saat kumparan yang berada di dalam tengah-tengah medan magnet dialiri listrik dari batrei maka kumparan berarus 
tersebut akan memotong medan magnet diantara kutub Utara dan kutub Selatan, dari peristiwa tersebut akan timbul gaya yang akan membuat kumparan berputar.

2.3.2.1 Jenis-Jenis Motor Listrik

Tipe atau jenis motor listrik yang ada saat ini beraneka ragam jenis dan tipenya. Semua jenis motor listrik yang ada memiliki 2 bagian utama yaitu stator dan rotor. Stator adalah bagian motor listrik yang diam dan rotor adalah bagian motor listrik yang bergerak (berputar).Pada dasarnya motor listrik dibedakan dari jenis sumber tegangan kerja yang digunakan. Berdasarkan sumber tegangan kerjanya motor listrik dapat dibedakan menjadi dua jenis yaitu :

1. Motor listrik arus bolak-balik AC (Alternating Current)

Motor Listrik Arus Bolak-Balik (AC) adalah jenis motor listrik yang beroperasi dengan sumber tegangan arus listrik bolak balik (AC, Alternating Current).

2. Motor listrik DC (arus searah)

Mesin arus searah dapat berupa generator DC atau motor DC. Generator DC alat yang mengubah energi mekanik menjadi energi listrik DC.Motor DC alat yang mengubah energi listrik DC menjadi energi mekanik putaran. Sebuah motor DC dapat difungsikan sebagai generator atau sebaliknya generator DC dapat difungsikan sebagai motor DC.

\subsubsection{Daya Penggerak}

Secara umum daya diartikan sebagai kemampuan yang dibutuhkan untuk melakukan kerja, yang dinyatakan dalam satuan Watt, ataupun Hp. Penentuan besar daya yang dibutuhkan perlu memperhatikan beberapa hal yang mempengaruhinya, diantaranya adalah torsi, dan berat yang bekerja pada mekanisme tersebut.

Berikut adalah rumus untuk mencari daya dan torsi:

1. Mencari Daya (P)

$$
\begin{array}{ll}
\mathrm{P}=1 / 2 \mathrm{HP} & \longrightarrow \mathrm{AC}(1 \mathrm{HP}=745,7 \mathrm{~W}) \\
\mathrm{P}=\omega . \mathrm{T} & \\
\text { Dimana }: \omega=n \cdot \frac{2 \pi}{60} & \mathrm{rad} / \mathrm{s} \ldots \ldots \ldots \ldots \ldots \ldots \ldots \ldots \ldots \ldots \ldots
\end{array}
$$

2. Mencari Torsi (T)

$$
\begin{aligned}
& \mathrm{T}=\frac{\mathrm{P}}{\omega}=\frac{60 . P(\eta \cdot f e)}{2 \pi n} \quad \ldots \ldots \ldots . . . \\
& \text { Dimana }: \eta=\frac{P \text { output }}{P} \times 100 \%
\end{aligned}
$$

Keterangan :

$\mathrm{P}$ : Daya $(\mathrm{W})$

$\omega:$ Kecepatan sudut $(\mathrm{rad} / \mathrm{s})$

$\eta=$ Efisiensi

fe : Faktor koneksi transmisi belt $=1$

\subsubsection{Pasak}

Pasak adalah sebuah elemen mesin berbentuk silindrik, balok kecil atau silindrik silindrik tirus yang berfungsi sebagai penahan elemen seperti puli, sprocket roda gigi atau kopling pada poros. Jika pasak tidak terpasang dengan benar antara puli dengan poros maka kemungkinan akan terjadi slip diantara bagian yang berkontak. Keausan akan dialami oleh lubang puli bila terjadi slip. Untuk itu perlu perancangan pasak yang benar agar mendapatkan hasil yang optimal. Berikut adalah beberapa jenis pasak :

\subsubsection{Pasak Parallel Persegi / Bujur Sangkar}

Salah satu jenis pasak yang banyak dipakai dalam berbagai aplikasi adalah pasak parallel persegi atau pasak parallel bujur sangkar. Untuk poros berdiameter hingga 6,5 inch, pasak berpenampang lebih disukai, sedangkan pasak berpenampang persegi panjang diterapkan untuk poros berdiameter lebih besar.

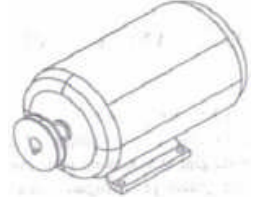

\subsubsection{Pasak Pin}

\section{Gambar 2.3 Pasak Bujur Sangkar Pada Motor Listrik dan Puli}

Pasak jenis ini dipasangkan antara hub (bagian dari puli, sprocket atau roda gigi) dan poros dengan menggunakan sebuah pin dengan berpenampang lingkaran. Untuk keperluan pemasangannya dibutuhkan sebuah lubang yang menembus antara hub dan poros. 


\subsubsection{Pasak pin ulir}

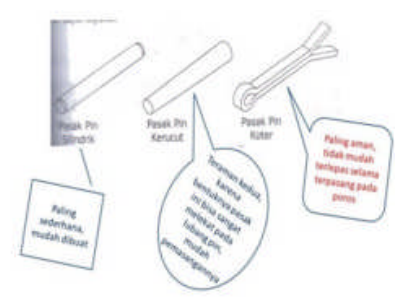

Pasak pin ulir dipasangkan pada lubang tembus antara poros dan hub, hanya saja metode pemasangannya dan pengencangannya dengan ulir. Biasanya lubang pasak yang ada di hub dibuat berulir, sedangkan lubang pada poros dibuat rongga seadanya. Terkadang pasak pin ulir ini dapat digantikan perannya oleh sebuah baut berkepala segi enam.

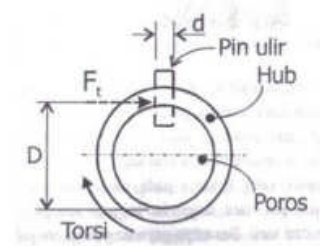

$\mathrm{F}=\frac{2 T}{D}$

Gambar 2.5 Gaya - gaya Pada Pasak Pin Ulir

Keterangan :

T:Nilai Torsi (N.m)

D:Diameter Puli (mm)

\subsubsection{Poros}

Poros adalah suatu bagian stasioner yang beputar, biasanya berpenampang bulat dimana terpasang elemenelemen seperti roda gigi (gear), pulley, flywheel, engkol, sprocket dan elemen pemindah lainnya.Poros bisa menerima beban lenturan, beban tarikan, beban tekan atau beban puntiran yang bekerja sendiri-sendiri atau berupa gabungan satu dengan lainnya.

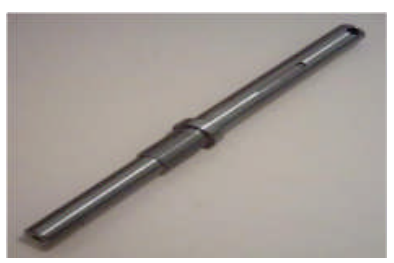

Gambar 2.6 Poros

Poros dapat diklasifikasikan berdasarkan beberapa hal.

\subsubsection{Berdasarkan Pembebanannya}

1. Poros Transmisi (transmission shafts)

Poros transmisi lebih dikenal dengan sebutan shaft. Shaft akan mengalami beban punter berulang, beban lentur berganti ataupun kedua - duanya. Pada shaft, daya dapat ditransmisikan melalui gear, belt pulley, sprocket rantai, dll.

2. Gandar

Poros gandar merupakan poros yang dipasang diantara roda - roda kereta barang.Poros gandar tidak menerima beban punter dan hanya mendapat beban lentur.

3. Poros Spindle

Poros spindle merupakan poros transmisi yang relatip pendek, misalnya pada poros utama mesin perkakas dimana beban utamanya berupa beban punter. Selain beban punter, poros spindle juga menerima beban lentur (axial load). Poros spindle dapat digunakan secara efektif apabila deformasi yang terjadi pada poros tersebut kecil.

\subsubsection{Berdasarkan Bentuknya}

1. Poros Lurus

2. Poros engkol sebagai punggerak utama pada silinder mesin. 
Ditinjau dari segi besarnya transmisi daya yang mampu ditransmisikan, poros merupakan elemen mesin yang cocok untuk mentransmisikan daya yang kecil hal ini dimaksudkan agar terdapat kebebasan bagi perubahan arah (arah momen putar).

\subsubsection{Dalam Perancangan Poros Perlu Diperhatikan Beberapa Hal}

\section{Kekuatan Poros}

Poros transmisi akan menerima beban puntir (twisting moment), beban lentur (bending moment) ataupun gabungan antara beban puntir dan lentur. Dalam perancangan poros perlu memperhatikan beberapa factor, misalnya : kelelahan, tumbukan dan pengaruh konsentrasi tegangan bila menggunakan poros bertangga ataupun penggunaan alur pasak pada poros tersebut. Poros yang dirancang tersebut harus cukup aman untuk menahan beban - beban tersebut.

\section{Kekakuan Poros}

Meskipun sebuah poros mempunyai kekuatan yang cukup aman dalam menahan pembebanan tetapi adanya lenturan atau defleksi yang terlalu besar akan mengakibatkan ketidak telitian (pada mesin perkakas), getaran mesin (vibration) dan suara (noise). Oleh karena itu disamping memperhatikan kekuatan poros, kekakuan poros juga harus diperhatikan dan disesuaikan dengan jenis mesin yang akan ditransmisikan gayanya dengan poros tersebut.

3. Putaran Kritis

Bila putaran mesin dinaikan maka akan menimbulkan getaran (vibration) pada mesin tersebut. Batas antara mesin yang mempunyai jumlah putaran normal dengan putaran mesin yang menimbulkan getaran yang tinggi disebut putaran kritis.Hal ini dapat terjadi pada turbin, motor bakar, motor listrik, dll.Selain itu timbulnya getaran yang tinggi dapat mengakibatkan kerusakan pada poros dan bagian - bagian lainnya.Jadi dalam perancangan poros perlu mempertinbangkan putaran kerja dari poros tersebut agar lebih rendah dari putaran kritisnya.

\section{Material Poros}

Poros yang biasa digunakan dalam putaran tinggi dan bebas yang berat pada umumnya dibuat dari baja paduan denga proses pengerasan kulit sehingga tahan terhadap kausan. Beberapa diantaranya adalah baja khrom nikel, baja khrom, baja khrom molibden, dll.

Sekalipun demikian, baja paduan khusus tidak selalu dianjurkan jika alasannya hanya putaran tinggi dan pembebanan yang berat saja. Dengan demikian perlu dipertimbangkan pemilihan jenis heat treatment yang tepat untuk kekuatan maksimal.

- Bahan poros=ST 42 dengan density $7800 \mathrm{~kg} / \mathrm{m}^{3}$

- Panjang poros $=250 \mathrm{~mm} \quad=0,25 \mathrm{~m}$

- Diameter $\quad=19 \mathrm{~mm}=0,019 \mathrm{~m}$

2.3.5 Pulley

Pulley digunakan untuk memindahkan daya dari satu poros ke poros yang lain dengan alat bantu sabuk. Karena perbandingan kecepatan dan diameter berbanding terbalik, (Gambar 2.7), maka pemilihan pulley harus dilakukan dengan teliti agar mendapatkan perbandingan kecepatan yang diinginkan.Diameter luar digunakan untuk alur sabuk dan diameter dalam untuk peanmpang poros.

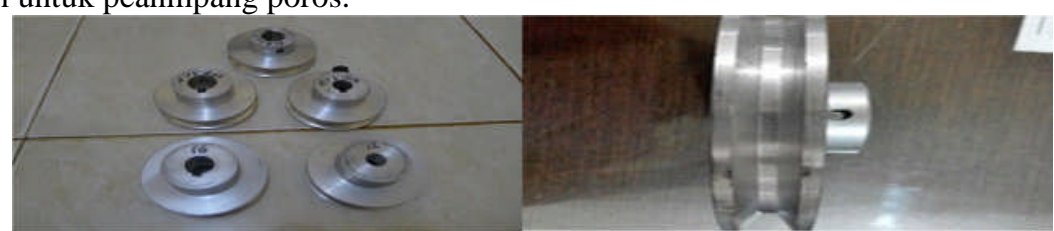

\section{Gambar 2.7 Pulley Alumunium Alur V}

Puli biasanya terbuat dari besi tuang, dan alumunium, bagian luar puli dibuat llicin supaya sabuk dapat berjalan dengan baik dan tidak cepat aus,

\subsubsection{Macam-macam Puli}

\section{Puli alur}

Pada puli jenis alur ini ada yang terdiri dari alur rata dimana dalam hubungan dengan sabuk yang berpenampang $\mathrm{V}$ juga alur $\mathrm{V}$ ganda yang menggunakan sabuk berbentuk $\mathrm{V}$ dan alur V.Terlihat pada gambar 2.8.

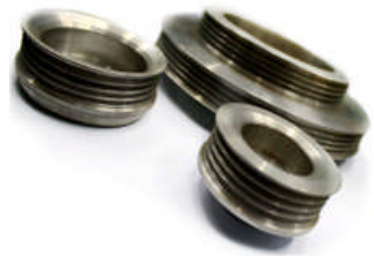




\section{Puli jenis tingkat}

\section{Gambar 2.8 Puli Alur}

Puli ada yang bertingkat satu atau tunggal dimana hanya menggunakan satu sabuk dan bertingkat dua yang menggunakan sabuk ganda. Nampak pada Gambar 2.9.

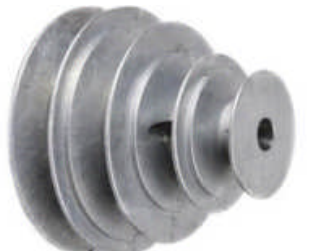

\section{Gambar 2.9 Puli Tingkat}

Ada beberapa material yang digunakan untuk membuat puli, setiap masing-masing bahan material mempunyai karateristik yang berbeda-beda.

\subsubsection{Bahan Pada Puli}

1. Puli Besi Tuang

Puli yang berbahan baku dari besi kasar dan dicampur karbon yang dilebur dan dituang kedalan cetakan berbentuk puli (Gambar 2.10).

1) Kelebihan

a) Menghasilkan kombinasi kekuatan tarik dan tekan yang baik.

b) Tahan terhadap keausan, gerusan, dll.

c) Tidak berkarat

2) Kekuranag

a) Tidak dapat disambung dengan paku keling atau dilas, dua buah besi tuang hanya dapat disambung dengan baut dan sekrup.

b) Tidak dapat diberi muatan magnet.

c) Getas sehingga tidak dapat menahan lenturan.

\section{Puli Besi baja}

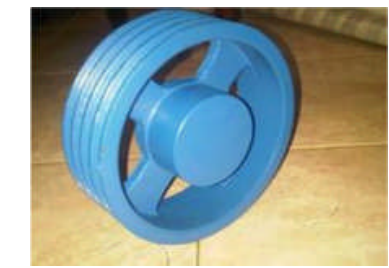

\section{Gambar 2.10 Puli Besi Tuang}

Puli ini terbuat dari logam paduan, logam besi sebagai unsur dasar dengan beberapa elemen lainnya, termasuk karbon. Dilihat pada gambar 2.11. Kandungan unsur karbon dalam baja berkisar antara $0,2 \%$ hingga $2,1 \%$ berat sesuai grade-nya.

1) Kelebihan

a) Kuat tarik tinggi.

b) Bisa dilas atau didaur ulang.

2) Kekurangan
a) Bisa berkarat.
b) Lemah terhadap gaya tekan.
c) Tidak fleksibel
d) Tidak kokoh
e) Tidak tahan api

3. Puli Alumunium

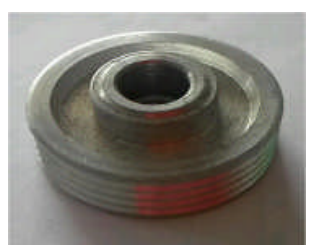

\section{Gambar 2.11 Puli Besi Baja}


Puli yang berbaha dasar alumunium ini proses pembuatannya menggunakan teknik pembubutan. Terlihat pada gambar 2.7 diatas.

1) Kelebihan

a) Lebih ringan

b) Mudah dibentuk

c) Murah

d) Tidak berkarat

2) Kekurangan

a) Kekuatan yang lebih rendah

b) Tidak mudah diperbaiki atau diluruskan ulang

c) Mudah fatigue (lelah), lebih mudah patah saat ada gangguan pada struktur logamnya

4. Puli Kayu

Pada dasarnya kayu merupakan bahan alam yang banyak memiliki kelemahan struktural, sehingga pengunaan kayu sebagai bahan puli perlu memperhatikan sifat dari kayu tersebut (Gambar 2.12). Oleh sebab itu, maka struktur kayu kurang populer dibandingkan dengan besi dan baja.

1) Kelebihan

a) Tahan terhadap pengaruh kimia dan listrik.

b) Relatif mudah dikerjakan dan diganti.

c) Mudah didapatkan, relatif murah.

2) Kekurangan

a) Jenis kayu kurang awet.

b) Kekuatannya sangat dipengaruhi oleh jenis kayu, mutu, kelembaban dan pengaruh waktu pembebanan.

c) Keterbatasan ukuran, berskala besar dan tinggi.

d) Mudah aus.

\subsubsection{Perhitungan Gaya- Gaya Pada Pulli}

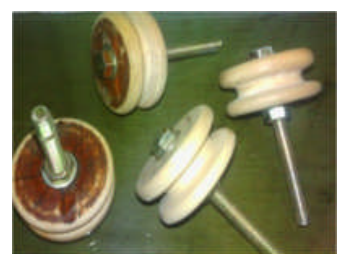

Gambar 2.12 Puli Kayu

1. Puli terbuat dari bahan alumunium dengan density $2700 \mathrm{~kg} / \mathrm{m}^{3}$

2. Mencari diameter puli $\left(\mathrm{D}_{1}\right)$

$\sigma \mathrm{t}=\rho \cdot \mathrm{v}^{2}$

$\mathrm{v}^{2}=\frac{\sigma t}{\rho}$

Keterangan :

$\rho=$ Density dari material $\quad=2700 \mathrm{~kg} / \mathrm{m}^{2}$

$\mathrm{v}=$ Velocity of run $\quad=\frac{\pi D N}{60}$

$\sigma \mathrm{t}=$ Sentrifugal strees puli $=4,5 \mathrm{Mpa}=4,5.10^{6} \mathrm{~N} / \mathrm{m}^{2}$

3. Ukuran tangan/arm

$\mathrm{m}=\frac{2 T}{n}$

- Untuk 20 sampai 30 - v belt puli

- Ketebalan puli $(B)=25 \%$ x belt

- Untuk tangan/arm $=n=4$ untuk $\Phi 200 \mathrm{~mm}$ sampai $600 \mathrm{~mm}$

4. Modulus section $\mathrm{n}=6$ untuk $\Phi 600 \mathrm{~mm}$ sampai $1500 \mathrm{~mm}$

$\mathrm{Z}=\frac{\pi}{32} \times \mathrm{b}_{1} \cdot\left(\mathrm{a}_{1}\right)^{2}$

Keterangan :

$\mathrm{b}_{1}=$ Minor axis

$a_{1}=$ mayor axis $=2 b_{1}$

5. Formula bending strees

$\sigma \mathrm{B}=\frac{m}{Z}$ 
6. Mencari diameter puli $\left(\mathrm{D}_{2}\right)$

$\frac{\mathrm{N}_{1}}{\mathrm{~N}_{2}}=\frac{\mathrm{D}_{2}}{\mathrm{D}_{1}}=\mathrm{D}_{2}=\frac{\mathrm{N}_{1} \cdot \mathrm{D}_{1}}{\mathrm{~N}_{2}}$

Keterangan :

$\mathrm{D}_{1}=$ Diameter penggerak $(\mathrm{mm})$

$\mathrm{D}_{2}=$ Diameter puli yang digerakam $(\mathrm{mm})$

$\mathrm{N}_{1}=$ Putaran motor $=1400 \mathrm{rpm}$

$\mathrm{N}_{2}=$ Putaran sprocket $=100 \mathrm{rpm}$

\subsubsection{Sabuk}

Sabuk biasanya digunakan untuk memindahkan putaran motor keporos yang jaraknya tidak memungkinkan untuk menggunkan tranmisi roda gigi. Ada dua sabuk yang digunakan sebagai transmisi, jarak yang jauh antar dua buah poros yang digunakan sebagai transmisi dengan menggunakan roda gigi. Macam sabuk (belt) dikelompokkan menjadi tiga yaitu:

1. Sabuk terbuka, yang terdiri dari:

a) Sabuk terbuka tanpa puli pemegang

b) Sabuk terbuka dengan puli pemegang

c) Sabuk trbuka yang menggerakkan beberapa poros

2. Sabuk silang

a) Sabuk silang biasa

b) Sabuk silang tegak lurus tanpa puli pengantar

c) Sabuk silang tegak lurus dengan puli pengantar

3. Sabuk penggerak

Sabuk penggerak adalah suatu peralatan dari mesin-mesin yang bekerja berdasarkan geseran. Perpindahan gaya ini bergantung pada tekanan sabuk penggerak kepermukaan puli. Oleh karena itu ketegangan dari sabuk penggerak sangatlah penting bila terjadi slip, kekuatan gerakannya berkurang, adapun macamnya sebagai berikut.

a) Sabuk penggerak datar

1) Sabuk penggerak datar biasa

2) Sabuk penggerak datar berurut

3) Sabuk penggerak datar positif

b) Sabuk penggerak - V

Sabuk penggerak $\mathrm{V}$ dapat ditemukan dalam bermacam-bermacam standar dan tipe untuk memindahkan daya. Dalam pembuatan mesin pengayak pasir ini menggunakan sabuk V-Belt tipe A karena memiliki beberapa kelebihan, antara lain:

1. V - Belt lebih kompak.

2. Slip kecil dibanding flat'

3. Operasi lebih tenang.

4. Mampu meredam kejutan saat start.

Tenunan teteron atau semacamnya dipergunakan sebagai inti sabuk untuk membawa tarikan yang besar sabuk$\mathrm{V}$ dililitkan pada keliling alur puli yang berbentuk V pula. Adapun bentuk kontruksi macam-macam penampang $V$ belt yang umum dipakai terlihat pada (Gambar 2.13).

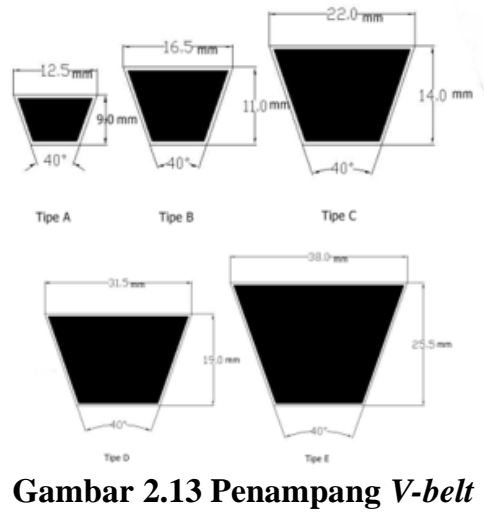

1. Untuk menentukan panjang keliling sabuk ( L)

$\mathrm{L}=\frac{\pi}{2}\left(\mathrm{D}_{2}+\mathrm{D}_{1}\right)+2 \mathrm{X}+\frac{\left(\mathrm{D}_{2}-\mathrm{D}_{1}\right)^{2}}{4 \mathrm{X}}$ 
(Khurmi, R.S, 2005, Hal 335)

Keterangan :

L : Panjang sabuk (mm)

$\mathrm{X}$ : Jarak sumbu poros $(400 \mathrm{~mm})$

$\mathrm{D}_{1}$ :Diameter puli penggerak $(\mathrm{mm})$

$\mathrm{D}_{2}$ :Dameter yang digerakkan $(\mathrm{mm})$

2. Kecepatan linier sabuk ( V )

$$
\mathrm{V}=\frac{\pi \mathrm{D} \mathrm{N}}{60}
$$

3. Mencari $\mathrm{T} 1$ dan $\mathrm{T} 2$

$$
\begin{aligned}
& \mathrm{T} 1=\mathrm{T}-\mathrm{Tc} \\
& \mathrm{Tc}=\dot{\mathrm{m}} \cdot \mathrm{v}^{2}
\end{aligned}
$$$$
\text { Dimana : } \dot{\mathrm{m}}=\mathrm{bt} \text {. L . } \rho
$$

\section{Keterangan:}

$\mathrm{Tc}=$ Centrifugal tension $\mathrm{kg} / \mathrm{m}$

$\rho=$ Bahan belt (Leather $100 \mathrm{~kg} / \mathrm{m}^{3}$ )

$\dot{\mathrm{m}}=$ Mass of the belt per matre leght $\mathrm{kg} / \mathrm{m}$

4. Power transmition by belt

$$
\mathrm{P}=(\mathrm{T} 1-\mathrm{T} 2) . \mathrm{V}
$$

\subsubsection{Bantalan Atau Bearing}

Bantalan adalah elemen yang menumpu poros beban, sehingga putaran atau gerakan bolak balik dapat berlangsung secara halus, aman dan panjang umurnya (life time).Bantalan harus cukup kokoh untuk memungkinkan poros serta elemen mesin lainnya bekerja dengan baik. Jika bantalan tidak berfungsi dengan baik maka prestasi seluruh system akan menurun atau tidak dapat bekerja dengan semestinya. Jadi bantalan dalam permesinan dapat disamakan peranannya dengan potensi pada gedung. Bantalan dapat diklasifikasikan sebagai berikut :

1. Atas dasar gerakan bantalan terhadap poros

a. Bantalan luncur

Pada bantalan ini terjadi gesekan luncur antara poros dan bantalan karena permukaan poros ditumpu oleh permukaan bantalan dengan perantaraan lapisan pelumas.

b. Bantalan gelinding

Pada bantalan ini terjadi gesekan gelinding antara bagian yang berputar dengan bagian yang diam melalui elemen seperti peluru, rol atau rol jarum dan rol baut.

2. Atas dasar arah beban terhadap poros

a. Bantalan radial

Arah beban yang ditumpu bantalan ini adalah tegak lurus sumbu poros.

b. Bantalan radial

Arah bantalan ini adalah sejajar dengan sumbu poros.

c. Bantalan gelinding khusus

Bantalan ini dapat menumpu beban yang arahnya sejajar dan tegak lurus sumbu poros.

3. Perbandingan antara bantalan luncur dan bantalan gelinding

Bantalan luncur mampu menahan poros perputaran tinggi dengan beban besar.Bantalan ini sederhana kontruksinya dan dapat dibuat serta dipasang dengan mudah.Karena gesekannya yang besar pada waktu mulai jalan, bantalan luncur memerlukan momen awal yang besar.Pelumasan pada bantalan ini tidak begitu sederhana.Panas yang timbul dari gesekan yang besar, terutama dari beban yang besar, memerlukan pendingin khusus. Sekalipun demikian, karena adanya lapisan pelumas, bantalan ini dapat merendam tumbukan dan getaran sehingga hamper tidak bersuara.Tingkat ketelitian yang diperlukan tidak setinggi bantalan gelinding sehingga lebih murah.Bantalan gelinding umumnya lebih cocok untuk beban lebih kecil daripada bantalan luncur, tergantung pada bentuk elemen gelindingnya. Putaran pada bantalan ini dibatasi oleh gaya sentrifugal yang timbul pada elemen gelinding tersebut. Karena kontruksinya yang sukar dan ketelitiannya yang tinggi, maka bantalan gelindingnya hanya dapat dibuat oleh pabrik-pabrik tertentu saja.Adapun harganya pada umumnya lebih mahal dari bantalan luncur.Untuk menekan biaya pembuatan serta memudahkan pemakaian, bantalan gelinding di produksikan menurut standar dalam ukuran dan bentuk.Keunggulan bantalan ini adalah pada gesekannya yang rendah. Pelumasannyapun sangat sederhana yaitu cukup dengan gemuk bahkan pada bantalan yang memakai seal sendiri tidak memerlukan pelumasan lagi. Meskipun ketelitiannya sangat tinggi, namun karena adanya elemen gelinding dan sangkar, pada putaran tinggi bantalan ini sedikit gaduh dibandingkan dengan bantalan luncur. 
Pada waktu memilih bantalan, ciri masing-masing harus dipertimbangkan sesuai dengan pemakaiannya, lokasi dan macam beban yang akan dialami.

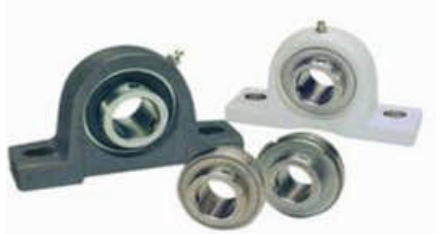

Gambar 2.14 Bantalan / Bearing

Dalam perencanaan ini akan digunakan bearing jenis Ball Bearing. Geometri Ball Bearing dapat dilihat pada Gaambar 2.15.

\subsubsection{Kawat Saringan}

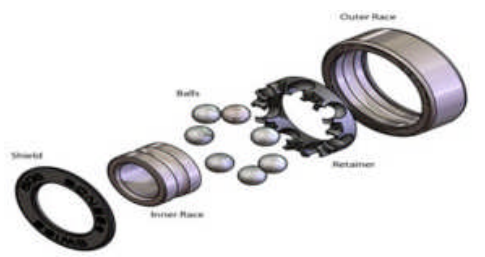

\section{Gambar 2.15 Geometri Ball Bearing}

Kawat saringan yang digunakan adalah stainless steel Type-304 nomor 9226w242 yang ukuran saringannya 25 x 25 lobang tiap inch dengan diameter kawat 0.018 inch $(0,0004572 \mathrm{~m})$.

\subsubsection{Dimensi Bak Penyaring}

Bak saringan yang direncanakan adalah :

1. panjang bak saringan $=800 \mathrm{~mm}=0,80 \mathrm{~m}$

2. lebar bak saringan $\quad=500 \mathrm{~mm}=0,50 \mathrm{~m}$

3. tinggi bak saringan $\quad=90 \mathrm{~mm}=0,09 \mathrm{~m}$

4. Tinggi maksimum material $=30 \mathrm{~mm}=0,03 \mathrm{~m}$

2.3.8.2 Mencari Kapasitas

1. Mencari kecepatan material (V).

$\mathrm{V}=4.166 \mathrm{put} / \mathrm{s} \times 0,01 \mathrm{~m} / \mathrm{put}$

2. Mencari luas penampang aliran (A). $\mathrm{A}=\mathrm{L} \times \mathrm{T}$

3. Mencari kapasitas material $(\mathrm{Q})$.

$\mathrm{Q}=\mathrm{V} \times \mathrm{A} \times 3600 \mathrm{~s} / \mathrm{jam}\left(\mathrm{m}^{3} / \mathrm{jam}\right)$

$\mathrm{Q}=\mathrm{Q} \times$ masa jenis pasir (ton $/ \mathrm{jam}$ )

4. Volume maksimum material pada bak saringan (v). $\mathrm{v}=\mathrm{P} \times \mathrm{Lx} \mathrm{T}$

5. Masa material pada bak saringan (m). $\mathrm{m}=\mathrm{v} \cdot \mathrm{P}$ 


\section{METODE PENELITIAN}

\subsection{Diagram Alir Perancangan}

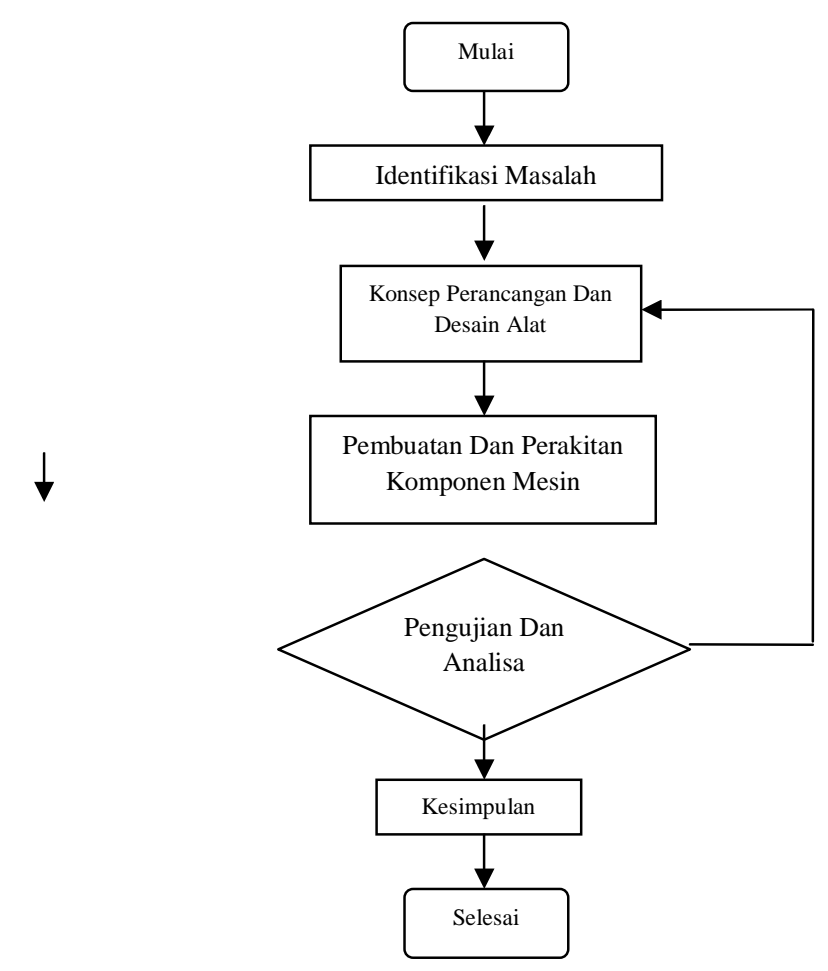

\section{Gambar 3.1 Diagram Alir Perancangan}

\subsection{Metode Penelitian}

Dalam melakukan proses penelitian ini, penulis menggunakan metode kuantitatif. Metode penelitian kuantitatif diartikan sebagai metode penelitian yang berlandaskan pada filsafat positivisme, yaitu memandang realitas / gejala / fenomena yang diklasifikasikan, relatif tetap, konkrit, teramati, terukur, dan hubungan gejala sebab akibat.

Dalam penulisan Tugas Akhir ini, penulis melakukan penelitian dan pembuatan alat di Menawan Teknik dengan proses penelitian sebagai berikut :

1. Persiapan Awal

Mempersiapkan hal - hal yang perlu untuk penelitian, membuat permohonan Tugas Akhir, dan konsultasi pada dosen pembimbing.

2. Studi Perpustakaan

Studi literatur yaitu mempelajari buku - buku karangan ilmiah yang berhubungan dengan masalah yang dihadapi.

3. Pengumpulan Data

Pengumpulan data yang akan digunakan untuk penyusunan laporan Tugas Akhir dengan cara melihat buku buku yang bersangkutan dengan judul Tugas Akhir dan pengamatan langsung mesin yang akan dirancang.

4. Perancangan dan Pembuatan Alat

Yakni proses perancangan dan pembuatan alat pada Menawan Teknik.

5. Analisa dan Evaluasi Data

Yakni data yang diperoleh dianalisa dan dievaluasi bersama-sama dosen pembimbing.

6. Internet

Digunakan untuk mencari data - data penunjang yang dibutuhkan dalam penyusunan Laporan Tugas Akhir.

7. Bimbingan

Melaporkan hasil penulisan Tugas Akhir kepada dosen pembimbing.

\subsection{Kebutuhan Bahan Utama}


Tabel 3.1 Bahan Utama

\begin{tabular}{|c|l|c|c|}
\hline No & \multicolumn{1}{|c|}{ Nama Bahan } & Satuan & Jumlah \\
\hline 1 & Besi siku & Meter & 12 \\
\hline 2 & Besi hollow & Meter & 12 \\
\hline 3 & Motor ac & Pcs & 1 \\
\hline 4 & Kawat kasa & Meter & 1 \\
\hline 5 & Poros & Pcs & 1 \\
\hline 6 & Baut & Kg & 6 \\
\hline 7 & Plat & Lembar & 1 \\
\hline 8 & Bearing & Pcs & 6 \\
\hline
\end{tabular}

\subsection{Tahapan Perancangan Alat}

a. Persiapan dan pemotongan besi rangka.

b. Pengelasan rangka.

c. Pembuatan bak penampung.

d. Pembuatan saringan ayak.

e. Pembuatan poros piringan engkol.

f. Pemasangan motor listrik.

g. Pemasangan bantalan poros.

h. Pemasangan puli dan sabuk.

i. Pengecatan alat.

Perancangan alat selesai.

\section{ANALISA DAN PEMBAHASAN}

\subsection{Dimensi Bak Penyaring}
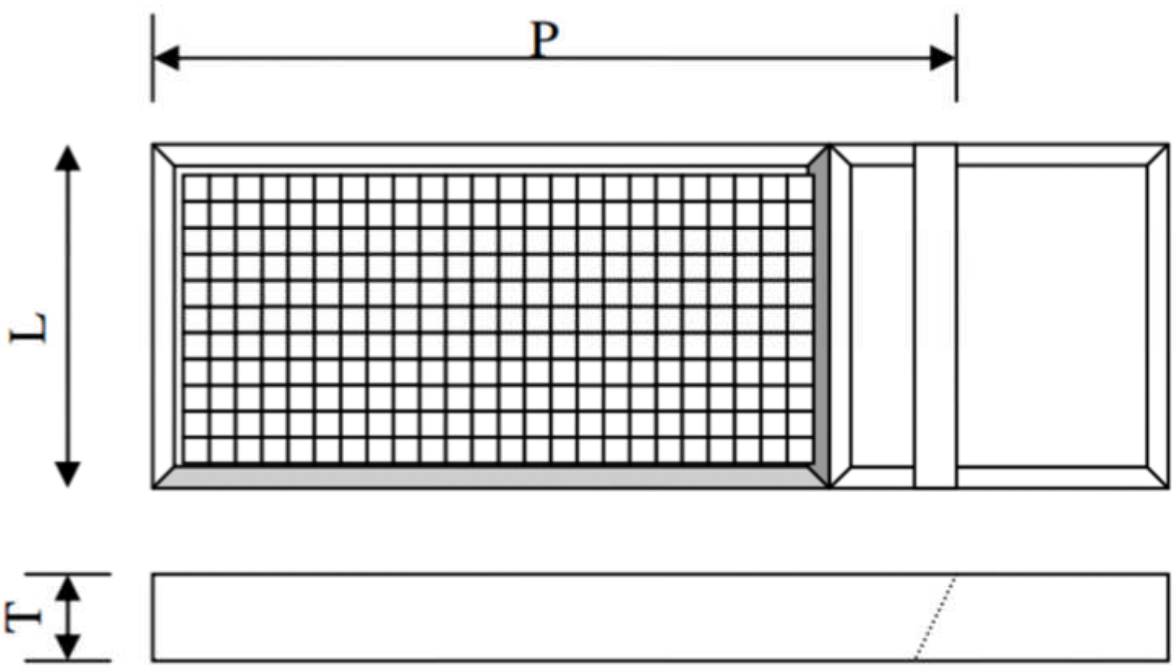

Gambar 4.1 Kerangka Bak Penyaring

Bak saringan yang direncanakan adalah :
Panjang bak saringan
$=800 \mathrm{~mm}=0,80 \mathrm{~m}$
Lebar bak saringan
$=500 \mathrm{~mm}=0,50 \mathrm{~m}$
Tinggi bak saringan
$=90 \mathrm{~mm}=0,09 \mathrm{~m}$
Tinggi maksimum material
$=30 \mathrm{~mm}=0,03 \mathrm{~m}$

Untuk tinggi pasir di bak penyaring diperkirakan $30 \mathrm{~mm}$. dan untuk saringan atau lobang saringan direncanakan adalah 25 × 25 lubang tiap inch dengan nomor 9226w242, diketahui diameter kawatnya 0,00045m (0,018 inch) dan lebarnya $0,0008 \mathrm{~m}(0,032$ inch). 


\subsection{Mencari Kapasitas}

1. Dalam menentukan kapasitas material, ditentukan oleh bak saringan dimana putaran yang direncanakan 1400rpm $=4,166$ putaran perdetik, dengan rencana kemiringan ayakan $6^{\circ}$, diperkirakan material bergerak turun $10 \mathrm{~mm}$ tiap putaran atau $0,01 \mathrm{~m} /$ putaran, maka dapat diasumsikan kecepatan material $(\mathrm{V})$.

$V=4,166 \mathrm{put} / \mathrm{s} \cdot 0,01 \mathrm{~m} / \mathrm{put}$

$V=0,04166 \mathrm{~m} / \mathrm{s}$

2. Luas penampang aliran (A)

$A=L . T$

$\mathrm{A}=0,50 \mathrm{~m} \cdot 0,03 \mathrm{~m}$

$A=0,015 \mathrm{~m}^{2}$

3. Dengan diketahuinya kecepatan turun material dan penampang aliran, maka kapasitas dapat ditentukan.

$Q=V . A .3600 \mathrm{~s} / \mathrm{jam}$

$Q=0,04166 \mathrm{~m} / \mathrm{s} .0,015 \mathrm{~m}^{2} .3600 \mathrm{~s} / \mathrm{jam}$

$Q=2,2 \mathrm{~m}^{3} / \mathrm{jam}$

4. Maka untuk mendapatkan kapasitas aliran dalam satuan $\mathrm{kg} / \mathrm{jam}$, kita harus tahu masa jenis dari pasir yaitu 1650 $\mathrm{kg} / \mathrm{m}^{3}$

$Q=Q \cdot$ masa jenis pasir

$Q=2,2 \mathrm{~m}^{3} / \mathrm{jam} \cdot 1650 \mathrm{~kg} / \mathrm{m}^{3}$

$Q=3630 \mathrm{~kg} / \mathrm{jam}$

$Q=3,630 \mathrm{ton} / \mathrm{jam}$

5. Volume maksimum material pada bak saringan (v).

$v=P \cdot L \cdot T$

$v=0,80 \mathrm{~m} \cdot 0,50 \mathrm{~m} \cdot 0,03 \mathrm{~m}$

$v=0,012 \mathrm{~m}^{3}$

6. Jadi masa material pada bak saringan (m).

$m=v \cdot \rho$

$m=0,012 \mathrm{~m}^{3} \cdot 1650 \mathrm{~kg} / \mathrm{m}^{3}$

$m=19,8 \mathrm{~kg}$

\subsection{Perancangan Pada Motor Listrik}

1. Daya $(\mathrm{P})$

$\mathrm{P}=1 / 2 \mathrm{HP}$

$\mathrm{P}=1 / 2.745,7 \mathrm{~W}$

$\mathrm{P}=373 \mathrm{~W}$

$\omega=\mathrm{n} \frac{2 \pi}{60} \mathrm{rad} / \mathrm{s}$

$\omega=1400 \frac{2 \cdot 3,14}{60}$

$\omega=146 \mathrm{rad} / \mathrm{s}$

2. Mencari Torsi (T)

$\mathrm{T}=\frac{60.373 \mathrm{Nm} / \mathrm{s} .0,9.1}{2 . \pi .1400 \mathrm{rad} / \mathrm{s}}$

$\mathrm{T}=2,29 \mathrm{Nm}$

3. Mencari Pasak (F)

$\mathrm{F}=\frac{2 \cdot 2,29}{50}$

$\mathrm{F}=0,09 \mathrm{~mm}$

\subsection{Perhitungan Pulley dan Sabuk}

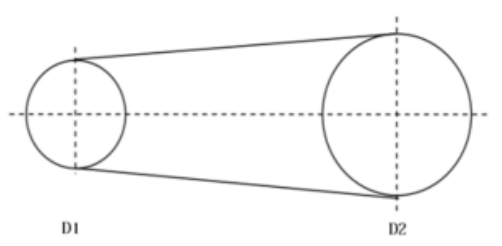

Gambar 4.2 Pulley dan $^{\text {pulley }}{ }_{2}$ 
1. Mencari diameter puli $\left(\mathrm{D}_{1}\right)$

- $\mathrm{V}^{2}=\frac{\sigma t}{\rho}$

$\mathrm{V}^{2}=\frac{4,5 \cdot 10^{6} \mathrm{~kg} / \mathrm{s}^{2} \mathrm{~m}}{2700 \mathrm{~kg} / \mathrm{m}^{2}}$

$\mathrm{V}^{2}=1,67 \mathrm{~m} / \mathrm{s}$

$\mathrm{V}=1,29 \mathrm{~m} / \mathrm{s}$

- $\mathrm{D}=\frac{60 \mathrm{~V}}{\pi N}$

$\mathrm{D}=\frac{60 \cdot 1,29 \mathrm{~m} / \mathrm{s}}{3,14 \cdot 1400 \mathrm{rad} / \mathrm{s}}$

$\mathrm{D}=0,17 \mathrm{~m}$

$\mathrm{D}=170 \mathrm{~mm}$

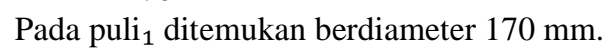

2. Mencari ukuran tangan/arm $\left(\mathrm{a}_{1}\right):(\Phi 170 \mathrm{~mm} \approx \mathrm{n}=4)$

$$
\begin{aligned}
\mathrm{m} & =\frac{2 T}{n} \\
\mathrm{~m} & =\frac{2 \cdot 2,29 \mathrm{Nm}}{4} \\
\mathrm{~m} & =1,145 \mathrm{Nm}
\end{aligned}
$$

3. Modulus section

$\mathrm{Z}=\frac{\pi}{32} \times \mathrm{b}_{1} \cdot\left(\mathrm{a}_{1}\right)^{2}$

$\mathrm{Z}=\frac{\pi}{32} \cdot 4 \mathrm{~b}_{1}^{3}$

$\mathrm{Z}=\frac{\pi b_{1}{ }^{3}}{8}$

4. Formula bending strees

$\sigma \mathrm{B}=\frac{m}{Z}=\frac{1,145 \mathrm{Nm}}{\pi \cdot\left(b_{1}\right)^{3}} \cdot 8$

$\mathrm{b}_{1}{ }^{3}=8,21 \cdot 10^{-7}$

$\mathrm{b}_{1}^{3}=5,53 \cdot 10^{-19}=0,009 \mathrm{~m}$

$a_{1}=2 . b_{1}=18 \mathrm{~mm}$

5. Mencari diameter puli $\left(\mathrm{D}_{2}\right)$

$\mathrm{D}_{1}$ (diameter puli) motor

$\mathrm{N}_{1}$ (putaran) motor

$$
=9 \mathrm{~mm}
$$

Direncanakan untuk $\mathrm{N}_{2}=100 \mathrm{rpm}$

$\mathrm{D}_{2}=\frac{N_{1} \cdot D_{1}}{N_{2}}$

$\mathrm{D}_{2}=\frac{1400 \mathrm{rpm} \cdot 170 \mathrm{~mm}}{100 \mathrm{rpm}}$

$\mathrm{D}_{2}=238 \mathrm{~mm}$

$\mathrm{Puli}_{2}$ ditemukan berdiameter $238 \mathrm{~mm}$.

6. Panjang sabuk (L)

Dalam menentukan panjang sabuk, terlebih dahulu diketahui jarak antara kedua poros, dimana jarak antara poros puli $_{1}$ dan poros puli ${ }_{2}$ adalah $600 \mathrm{~mm}$.

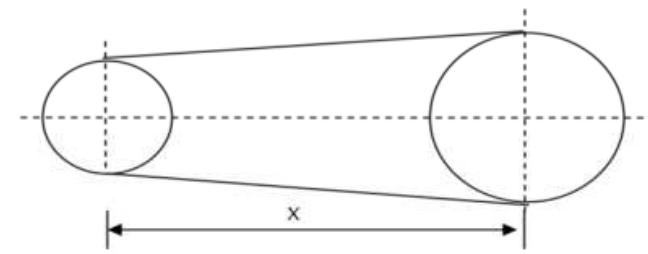

Gambar 4.3 Panjang Sabuk

$\mathrm{L}=\frac{\pi}{2}\left(\mathrm{D}_{2}+\mathrm{D}_{1}\right)+2 \mathrm{X}+\frac{\left(\mathrm{D}_{2}-\mathrm{D}_{1}\right)^{2}}{4 \mathrm{X}}$

$\mathrm{L}=\frac{\pi}{2}(238+170)+2.600+\frac{(238-170)^{2}}{4.600}$

$\mathrm{L}=2529 \mathrm{~mm}$

7. Kecepatan linier sabuk : ( $\max : 30 \mathrm{~m} / \mathrm{s})$ 
$\mathrm{V}=\frac{\pi D N}{60}$

$\mathrm{V}=\frac{3,14 \cdot 0,17 \cdot 1400}{60}$

$\mathrm{V}=12,45 \mathrm{~m} / \mathrm{s}<30 \mathrm{~m} / \mathrm{s}$

8. Mencari $\mathrm{T}_{1}$ dan $\mathrm{T}_{2}$

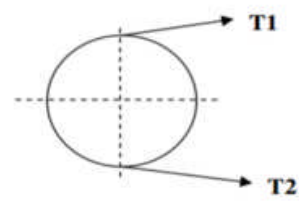

Gambar 4.4 Penampang $T_{1}$ dan $T_{2}$

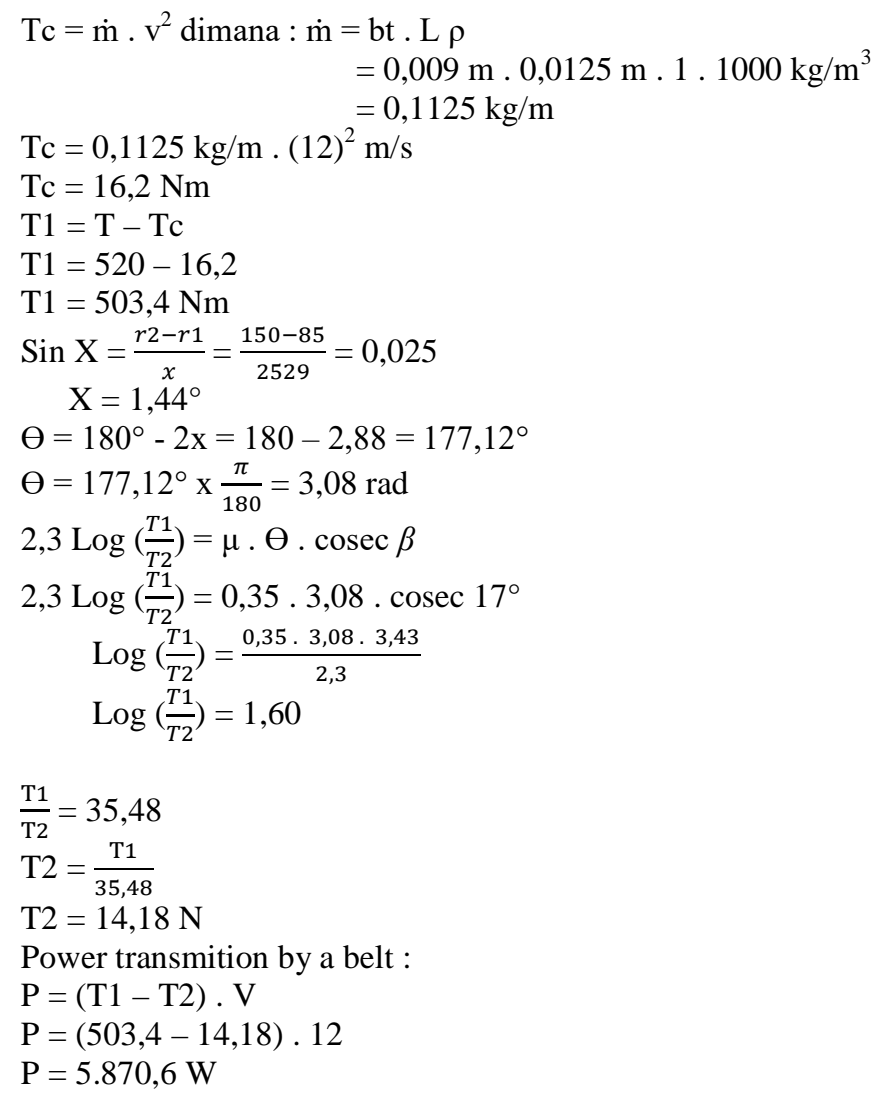

\section{PENUTUP}

\section{Kesimpulan}

Dari hasil pembahasan dan perhitungan yang dilakukan maka dapat diambil beberapa kesimpulan yaitu :

1. Prinsip kerja dari alat ini adalah dengan memanfaatkan motor listrik sebagai sumber tenaga yang diteruskan kepuli dengan transmisi sabuk, lalu diteruskan keputaran poros yang terpasang eksentrik pada pirigan engkol yang mengakibatkan ayakan akan bergerak berayun dan siap menerima pasir.

2. Puli penggerak berdiameter $50 \mathrm{~mm}$ dan puli yang digerakan berdiameter $300 \mathrm{~mm}$. Perbandingan puli pada poros penggerak dengan puli yang digerakan adalah $1: 6$.

3. Alat pengayak pasir ini bisa bongkar pasang sehingga digunakan untuk mengayak material pasir sesuai kebutuhan pemakai.

\section{DAFTAR PUSTAKA}


1. Sonawan, Heri.2014. PerancanganElemenMesin. Bandung: Alfabeta.

2. Suga, Kiyokatsu dan Sularso. 1991. Dasar Perencanaan dan Pemilihan Elemen Mesin. Jakarta: Pradnya Paramita.

3. http://www.kaskus.co.id/thread/51d1b3605a2acf1c5b000007/(diakses 27 Agustus 2016)

4. Joseph E. Shingley, Larry D Mitchell. 1996. PerancanganTeknikMesinJilid 2. Jakarta: Erlangga.

5. Khurmi, RS dan Gupta J.K. 2005.A Text Book Machine Design.New Delhi: Eurasia Publishing House (PVT) Ltd.

6. Robert, Vierck, Munaf, Dicky Rezady, 1986. Analisis Getaran (terjemahan). Penerbit Eresco, Bandung

7. Mappaita, Abdullah, 2005. Getaran Mekanik. Buku Ajar Jurusan Mesin Fakultas Teknik, Universitas Hasanuddin, Makassar.

8. Mappaita, Abdullah, 2004. Getaran Mekanik Lanjut. Buku Ajar Jurusan Mesin Fakultas Teknik, Universitas Hasanuddin, Makassar.

9. Paz Mario, Manu A., 1987. Dinamika Struktur Teori dan Perhitungan (terjemahan). Edisi kedua, Erlangga, Jakarta

10. Sitanggang, Nathanael 2007. Perencanaan Sambungan Profil Baja. (http://12a007001.studentsblog.undip.ac.id).

11. Supriatna, Nandan. Macam-Macam Alat Penyambung Baja. (http://file.upi.edu).

12. Szilard Rudolf, Wira, 1974. Teori dan Analisis Pelat (terjemahan). Erlangga Jakarta.

13. Thomson, W,T, Lea Prasetyo, 1986. Teori Getaran dengan Penerapannya (terjemahan). Edisi ke2, Penerbit Erlangga, Jakarta.

14. Timoshenko, s.woinowsky dan Krieger, Hindarko, 1992. Teori Pelat dan Cangkang (terjemahan). Erlangga, Jakarta.

15. William, W.Seto, Darwin Sebayang, 1985. Getaran Mekanis (terjemahan). Seri buku Schanm Teori dan Soal-soal, Penerbit Erlangga, Jakarta. 